\title{
Myeloperoxidase as an Important Predictor of Cardiovascular Risk in Individuals with Rheumatoid Arthritis
}

\section{Elisangela Gueiber Montes}

UEPG: Universidade Estadual de Ponta Grossa

Fabiana Postiglioni Mansani

UEPG: Universidade Estadual de Ponta Grossa

Alceu de Oliveira Toledo Júnior

UEPG: Universidade Estadual de Ponta Grossa

Marcelo Derbli Schafranski

UEPG: Universidade Estadual de Ponta Grossa

\section{Bruno Queiroz Zardo}

UEPG: Universidade Estadual de Ponta Grossa

\section{Fábio André dos Santos}

UEPG: Universidade Estadual de Ponta Grossa

\section{Sabrina Grassiolli}

UNIOESTE: Universidade Estadual do Oeste do Parana

\section{Lorena de Freitas Calixto}

UEPG: Universidade Estadual de Ponta Grossa

Romulo Lopes da Costa

UEPG: Universidade Estadual de Ponta Grossa

Felício de Freitas Netto

UEPG: Universidade Estadual de Ponta Grossa

José Carlos Rebuglio Vellosa ( $\sim$ josevellosa@yahoo.com.br)

UEPG: Universidade Estadual de Ponta Grossa https://orcid.org/0000-0003-4747-9197

\section{Research Article}

Keywords: corticotherapy, rheumatoid arthritis, cardiovascular risk, myeloperoxidase

Posted Date: July 8th, 2021

DOI: https://doi.org/10.21203/rs.3.rs-641421/v1 
License: (c) (i) This work is licensed under a Creative Commons Attribution 4.0 International License. Read Full License

Version of Record: A version of this preprint was published at Inflammopharmacology on November 26th, 2021. See the published version at https://doi.org/10.1007/s10787-021-00892-x. 


\section{Abstract}

Background: Rheumatoid arthritis is an inflammatory disease with joint manifestations. In the presence of extra-articular manifestations, the morbidity and severity of the disease increases. Glucocorticoid is used as a treatment and may result in side effects related to cardiovascular risk.

Methods: This was a cross-sectional study including 59 volunteers with rheumatoid arthritis receiving treatment at a Hospital of Campos Gerais, that aimed to establish the relation between cardiovascular risk, glucocorticoid treatment and myeloperoxidase in these patients. Subjects were divided into two groups: using $(n=39)$ and without glucocorticoids $(n=20)$. They underwent clinical evaluation, physical examination and blood samples were taken. Statistical analysis was performed using Student's t-test and Mann-Whitney test. Logistic regression was performed to assess cardiovascular risk. The significance level was $5 \%(a=0.05)$. Calculations were performed using the Statistical Package for the Social Science version 21.0 .

Results: There has been a significant difference between groups in blood glucose values $(p=0.012)$, that can be explained by the different percentage of diabetic patients in the groups. When assessed cardiovascular risk using the predictors of glucocorticoid dose, time of glucocorticoid use, myeloperoxidase, and C-reactive protein together, these were responsible for significantly predicting cardiovascular risk $(p=0.015)$.

Conclusions: A significant relation between the predictor myeloperoxidase alone was also demonstrated ( $p=0.037$ ), may it be an important predictor of cardiovascular risk among individuals with rheumatoid arthritis.

\section{Background}

Rheumatoid arthritis (RA) is a chronic inflammatory disease with great impact on the patient's life and society health care, whose prevalence rate ranges from $0.55 \%$ to $1.0 \%$ in the world population. This disease preferentially affects women, with peak incidence between 30 and 50 years [1] . It is characterized by peripheral, symmetrical polyarthritis, which leads to deformity and destruction of large and small joints. The severity of this pathology can increase overtime and may result in progressive development of joint destruction, deformity and significant decline in the functional capacity of the individual [2].

The clinical manifestations of RA can be divided into joint and extra joint [3], and in the latter situation, morbidity and severity of the disease increase, and may decrease life expectancy by 5 to 10 years in relation to the general population. This decrease is related to the higher risk of cardiovascular diseases (CVD), which is 2 to 5 times higher than in the general population $[4,5]$.

The reason why the prevalence of CVD occurs early and more intensely in patients with RA has been the subject of intense research. It is known that RA is related to the increase in the thickness of the intima 
and media layers of the common and femoral carotid arteries, a fact that correlated with severity and chronicity of rheumatologic disease [6].

Studies report that dyslipoproteinemia and inflammation of the endothelium are contributing factors to the most frequent atherosclerosis process in RA [7], but there is still a need for further research for elucidation about autoimmune participation on atherosclerosis and possible exogenous factors, including the treatment used in the disease [6].

The similarity of inflammation of rheumatoid synovitis, with inflammation occurring in atheroma, as well as corticosteroid therapy, make patients with RA the target of investigations into the complex inflammatory mechanism that occurs in atherosclerosis [8]. The two processes present common constituents such as elevated C-reactive protein (CRP), myeloperoxidase (MPO), cytokines and fibrinogen, suggesting that the association of factors present in systemic inflammation of AR may accelerate atherosclerosis $[9,10]$.

Despite the important improvement in the diagnosis and available treatments, a high morbidity of CVD still remains. This is due to the combination of different factors such as: chronic inflammatory features that predisposes to the development of comorbidities, ii) side effects of drugs used in the therapy (for example glucocorticoids -GCS), iii) the increased prevalence of traditional risk factors over, and iv) persistent disease activity, when this is more aggressive.

Acute myocardial infarction (AMI) is the main cause of death in Western civilization as the main consequence, of Coronary Artery Disease (CAD) [6].

From these data, it is important to evaluate the levels of biological markers importantly related to the increased risk of cardiovascular event, such as ultrasensitive C-Reactive Protein (us-CRP) and myeloperoxidase (MPO). [5,11].

Because it is an inflammatory pathology, RA therapy is based on therapeutic drugs with antiinflammatory action, being the first treatment used for inflammation of the disease based on the use of $S$ results in decreased activation, proliferation, differentiation and survival of various inflammatory cells. The higher the dose used in the treatment, the greater the effect [9]. However, long term use of GCS in patients with RA may result in deleterious side effects such as hyperglycemia, hepatosteatosis and insulin resistance (IR) [12].

The causes related to the association between RA and CVR have not yet been well studied, thus the present study aims to characterize RA patients' risk factors for cardiovascular diseases and evaluate possible predictors for CVD in individuals undergoing treatment with GCS.

\section{Methods}

This is an uncontrolled single-center cross-sectional study. All participants signed a Free and Informed Consent Form (FICF), approved by the Committee of Research Ethics of the State University of Ponta 
Grossa (UEPG) of number 1.879.373.

From April 2017 to June 2019, 59 patients with RA were selected, defined according to the classification criteria of the American College of Rheumatology [13], who were seen in the routine of the rheumatology outpatient clinic of the Regional University Hospital of Campos Gerais (HURCG), in the municipality of Ponta Grossa - Paraná, Brazil. The participants were referred to the University Laboratory of Clinical Analysis (ULCA) of UEPG, for blood collection and subsequent laboratory tests.

Pregnant women, individuals with neoplasms, other rheumatological autoimmune diseases, as well as those who presented some infectious process at the time of care were excluded from the study.

The 59 study participants were divided into two experimental groups considering the presence or not of treatment with GCS. Thus, the group with GCS was formed by 39 patients, while the group without GCS was formed by 20 patients.

The volunteers underwent clinical evaluation and a complete physical examination, which included a count of swollen and painful joints. Information was obtained through interviews and review of medical records. The history of dan each patient in disease-related aspects, such as clinical manifestations (including joint, extra-articular, comorbidities and risk factors for CAD), previous laboratory data and prescribed treatments (current and previous), and diagnostic criteria used, were evaluated.

Interviews and analysis of medical records were evaluated: age, gender, smoking, medications of current and previous use, presence of other autoimmune diseases, as well as history of chronic diseases, such as diabetes mellitus (DM), systemic arterial hypertension (SAH) and cardiovascular disease.

Systemic blood pressure of patients in a sitting position after at least five minutes of rest was determined. Two to three measurements were made for each individual and the purposes of analysis, the mean systolic blood pressure (SBP) and diastolic blood pressure (DBP) blood pressures were used. The patients were weighed and measured on a mechanical scale with anthropometric ruler, without shoes, to calculate body mass index. The waist and hip dimensions were also measured to calculate the waist/hip ratio.

The activity of RA was evaluated by calculating the Disease Activity Score index in 28 joints (DAS28). For this calculation, the following variables were used: count of 28 joints (right and left side: shoulders, elbows, wrists, metacarpanheralangeal, proximal interphalangeal of hands and knees) regarding the presence of pain and edema, us-CRP and visual scale of general health analog / overall activity of the disease evaluated by the patient, whose values range from zero to one hundred. Patients were classified according to Table 1 after DAS28 calculation as follow:

DAS 28-PCR $=0,56 * \sqrt{ }($ ARTDOL $)+0,28 * \sqrt{ }($ ARTEDEM $)+0,36 * \log (P C R+1)+0,014 * E V A+0,96$ ARTDOL: painful joint count in 28 joints, 
ARTEDEM: count of swollen joints in 28 joints,

VAS: score on the visual analog scale reported by the patient on his overall health assessment, on a scale of $0-100$.

Table 1 Classification of the patient regarding the intensity/activity of THE according to DAS28

\begin{tabular}{|ll|}
\hline DAS28 & Classification \\
\hline$<2.6$ & Remission (inactive disease) \\
\hline$\leq 2.6$ a $\leq 3.2$ & Light activity \\
\hline $3.2 \leq \leq 5.1$ & Moderate activity \\
\hline$>5.1$ & High activity \\
\hline
\end{tabular}

Source: Modified from Van Der Heijde et al [14]

Blood collection was performed by means of venous puncture with a 12-hour fasting patient. Approximately $10 \mathrm{~mL}$ of blood were collected from each patient, and the samples were transferred to different tubes for the analysis: tube 1 - containing anticoagulant EDTA $\mathrm{K}^{+}$used to perform glycated hemoglobin fraction $\mathrm{A}_{1 \mathrm{c}}\left(\mathrm{HBA}_{1 \mathrm{c})}\right.$, tube2 - containing sodium fluoride anticoagulant, used for centrifugation and separation of separate plasma, for serum glucose dosage according to the standard procedure of ULCA working routine and tube 3 - containing separator gel, being subsequently centrifuged (10 minutes/300 rpm) and the serum separated for different tests.

The us-CRP dosage was performed by the ultrasensitive immunoturbidimetric method-Wiener ${ }^{\circledR}$ and the Rheumatic Factor (RF) dosage was performed by semi-quantitative technique by the Wiener ${ }^{\circledR}$. The dosages of total cholesterol, HDL cholesterol, LDL cholesterol, glucose was performed by the enzymatic method in the CT300i Wiener ${ }^{\circledR}$. The measurements of insulin, troponin, Creatine Kinase Myocardial Bandmass (CKMB-mass) and homocysteine were performed by electrochemiluminescence in the COBAS e411 ${ }^{\circledR} 5$ generation. $\mathrm{Hba}_{1 \mathrm{C}}$ was dosed using methodology of High-Performance Liquid Chromatography (HPLC) methodology in the D-10 ${ }^{\circledR}$ Biorad.

Part of the serum sample of each patient was separated into aliquots of $300 \mu \mathrm{l}$ in microtubes, and then they were taken to the freezer at a temperature of $-80^{\circ} \mathrm{C}$, for subsequent measurement of myeloperoxidase, interleukin-1 $\beta$ (IL-1 $\beta$ ), interleukin - 6 (IL-6) and tumor necrosis factor-a (TNF-a).

IL-1 $\beta$ and IL- 6 dosages were performed through enzyme immunoassay (ELISA) methodology, using immuno tools reactive ${ }^{\circledR}$, following manufacturer's guidelines. For TNF-a was used reactive Sigma-Aldrich brand $^{\circledR}$ the ELISA methodology, following the manufacturer's guidelines. For the evaluation of myeloperoxidase levels, reactive Immunology Consultants Laboratory, Inc ${ }^{\circledR}$, through ELISA methodology, following the manufacturer's guidelines. The absorbances of these tests were read in synergy $\mathrm{H} 1$ 
microplate reader with control and software for reading Biotek's Gen $5^{\circledR}$ data (BioTek Instruments, Inc., Winooski, Vermont, USA).

The calculation for cardiac risk assessment was applied to the patients' data, according to the 2013 American College of Cardiology (ACC)/ American Heart Association (AHA), Guideline on the Treatment of Blood Cholesterol to Reduce Atherosclerotic Cardiovascular Risk in Adults [14] using the Heart Risk Calculator, taking into account: gender, age, smoking, ethnicity, diabetes, total cholesterol and HDL cholesterol values in $\mathrm{mg} / \mathrm{dL}, \mathrm{SBP}$ and DBP $(\mathrm{mm} \mathrm{Hg})$ and use of antihypertensive therapy.

For the evaluation of IR, the calculation of the HOMA-IR index was used the following formula:

\section{HOMA-IR = [glucose $(\mathrm{nmol} / \mathrm{L}) \times$ insulin $(\mu \mathrm{g} / \mathrm{mL}) / 22.5]$}

The results were analyzed with student $t$ tests for unpaired samples and Mann-Whitney nonparametric test. The non-parametric model was used only for the variables that even after transformation (logarithmic) did not present normal distribution (Kolmogorov Smirnov test, $\mathrm{p}<0.05$ ). The significance level adopted was $5 \%(a=0.05)$. All calculations were performed with the statistical package SPSS ${ }^{\circledR}$ (Statistical Package for the Social Science) version21.0 (SPSS Inc Chigaco Illinois USA).

It was constructed of a predictive model for cardiovascular risk through a logistic regression that included the following predictor variables: dose of GCS, time of use of GCS, serum myeloperoxidase and serum usCRP. After normality analysis performed with the Kolmogorov-Smirnov test, the variables did not present normal distribution $(p<0.0001)$, so they were dichotomized according to the reference values. Glucocorticoid dose: $\leq 7.5 \mathrm{mg} /$ day of prednisone (safe) and $>7.5 \mathrm{mg} /$ day (cardiovascular risk), Glucocorticoids use time: $\leq 3$ months (safe) and $>3$ months (cardiovascular risk), Myeloperoxidase: $\leq 350 \mathrm{ng} / \mathrm{mL}$ (normal) and $>350 \mathrm{ng} / \mathrm{mL}$ (high) and CRP: $\leq 0.3 \mathrm{mg} / \mathrm{dL}$ (low $/$ medium risk) and $>0.3 \mathrm{mg} / \mathrm{dL}$ (high risk). The dependent variable CVR was also dichotomized: low risk (<7.5) and high risk (>7.5). The values of the odds ratio (Odds Ratio (OR)) with a $95 \%$ confidence interval are presented. For the statistical model, the relationships were considered significant when $p<0.05$.

The equation of logistic regression ${ }^{(a)}$ was:

\section{(a) Logit $\left(p_{i}\right)=b_{0}+b_{1} \cdot x_{1, i}+\ldots+b_{k} \cdot x_{k, i}$}

The probability for the dependent binary variable, considering the predictor variables was (equation ${ }^{(b)}$ ):
b) $p=$
$1+\exp -\left(\beta_{0}+\beta_{1 . x_{1, i}}+\ldots+\beta_{\left.k, x_{k, i}\right)}\right.$

Where:

Logit $\left(P_{I)}\right.$ is the linear logistic function, 
$b_{0}$ is the constant,

bis the angular coefficient,

$x_{1}$ is the predictor variable,

$p$ is the probability,

exp is the basis of the Neperian logarithm.

All calculations were performed with the IBM-SPSS version 21 program (IBM Corp. âReleased 2012. IBM SPSS Statistics for Mac OS ${ }^{\circledR}$. Armonk, NY: IBM Corp.).

\section{Results}

The study included 59 patients diagnosed with RA, of whom 51 were women and 8 were men. Patients were categorized as to the use of GCS and CVR factors, such as smoking, DM and SAH were evaluated. No significant differences were found between the groups when these variables were evaluated. The results obtained are expressed in table 2 .

Table 2. Characterization of patients with rheumatoid arthritis according to glucocorticoid therapy. No glucocorticoids (GCS) and glucocorticoids (GCS) use. 


\begin{tabular}{|c|c|c|c|}
\hline Variables & $\begin{array}{l}\text { No GCS } \\
\text { (No. 20) }\end{array}$ & $\begin{array}{l}\text { GCS } \\
\text { (No. 39) }\end{array}$ & $\begin{array}{l}\text { Value of } \\
p\end{array}$ \\
\hline Age (years) ${ }^{\square}$ & $53.6 \pm 12.5$ & $52.2 \pm 11.2$ & $0.660^{\mathrm{ns}}$ \\
\hline \multicolumn{4}{|l|}{ Gender (\%)* } \\
\hline Female & $17(85)$ & $34(87)$ & $0.817^{\mathrm{ns}}$ \\
\hline Male & $3(15)$ & $5(13)$ & \\
\hline \multicolumn{4}{|l|}{ Smoking (\%)* } \\
\hline No & $16(80)$ & $26(67)$ & $0.284^{\mathrm{ns}}$ \\
\hline Yes & $4(20)$ & $13(33)$ & \\
\hline \multicolumn{4}{|c|}{ Hypertension (\%)* } \\
\hline No & $11(55)$ & $28(72)$ & $0.197^{\text {ns }}$ \\
\hline Yes & $9(45)$ & $11(28)$ & \\
\hline \multicolumn{4}{|l|}{ Diabetes (\%)* } \\
\hline No & $15(75)$ & $35(90)$ & $0.136^{\mathrm{ns}}$ \\
\hline Yes & $5(25)$ & $4(10)$ & \\
\hline \multicolumn{4}{|c|}{${ }^{\mathrm{a}}$ student $\mathrm{t}$ test for unpaired samples } \\
\hline \multicolumn{4}{|l|}{ *Test $\chi^{2}$} \\
\hline no significant & nce $(p \geq 0.05)$ & & \\
\hline
\end{tabular}

When comparing the anthropometric and metabolic profile of patients with and without GCS, no statistically significant differences were found between the groups considering Body Mass Index (BMI), waist-to-hip ratio, total cholesterol, HDL cholesterol, LDL cholesterol, triglycerides, homocysteine, troponin, HBA1c, insulin, HOMA-IR, CKMB-mass, SBP, DBP, RF, DAS28-PCR, IL-1 $\beta$, TNF-a, IL-6 and MPO, however the mean blood glucose was higher in patients who did not use corticosteroids, and this result was statistically significant $(p=0,012)$. The results obtained are presented in table 3 .

Table 3. Anthropometric and metabolic data compared between users and non-users of glucocorticoids. Average \pm SD and Median (interquartile range). 


\begin{tabular}{|c|c|c|c|}
\hline \multirow[t]{2}{*}{ Variables } & No GCS & GCS & $P$ value \\
\hline & (No. 20) & (No. 39) & \\
\hline \multirow[t]{2}{*}{$\operatorname{IMC}\left(\mathrm{kg} / \mathrm{m}^{2}\right)^{\square}$} & $28.9 \pm 5.1$ & $26.7 \pm 7.1$ & \multirow[t]{2}{*}{$0.230^{\mathrm{ns}}$} \\
\hline & $27.4(24.1-32.6)$ & $25.0(21.6-29.3)$ & \\
\hline \multirow[t]{2}{*}{ Waist ratio ${ }^{\square}$} & $0.9 \pm 0.1^{\#}$ & $0.9 \pm 0.1^{\# \# \#}$ & \multirow[t]{2}{*}{$0.521^{\mathrm{ns}}$} \\
\hline & $0.9 \quad(0.9-1.0)$ & $0.9(0.8-1.0)$ & \\
\hline \multirow[t]{2}{*}{ Total Cholesterol $(\mathrm{mg} / \mathrm{dL})^{\square}$} & $189.0 \pm 48.9$ & $203.6 \pm 46.3$ & \multirow[t]{2}{*}{$0.267^{\mathrm{ns}}$} \\
\hline & $181.0(148.5-238.3)$ & $216.0(183.0-234.0)$ & \\
\hline \multirow[t]{2}{*}{ Cholesterol HDL (mg/dL)* } & $52.2 \pm 13.7$ & $54.8 \pm 15.3$ & \multirow[t]{2}{*}{$0.530^{\mathrm{ns}}$} \\
\hline & $51.5(40.4-62.0)$ & $54.0(45.5-59.0)$ & \\
\hline \multirow[t]{2}{*}{ Cholesterol LDL (mg/dL) } & $111.6 \pm 40.2$ & $124.5 \pm 38.0$ & \multirow[t]{2}{*}{$0.230^{\mathrm{ns}}$} \\
\hline & $93.8(79.8-153.4)$ & $126.0(106.0-149.0)$ & \\
\hline \multirow[t]{2}{*}{ Triglycerides $(\mathrm{mg} / \mathrm{dL})^{\square}$} & $126.4 \pm 63.9$ & $129.4 \pm 55.7$ & \multirow[t]{2}{*}{$0.855^{\mathrm{ns}}$} \\
\hline & $105.5(82.0-172.5)$ & $116.0(90.0-116.4)$ & \\
\hline \multirow[t]{2}{*}{ Blood glucose $(\mathrm{mg} / \mathrm{dL}) *$} & $122.6 \pm 56.0$ & $99.0 \pm 40.4$ & \multirow[t]{2}{*}{$0.012^{s}$} \\
\hline & $103.5(87.5-122.0)$ & $90.0(83.0-98.0)$ & \\
\hline \multirow[t]{2}{*}{ Homocysteine $(\mu \mathrm{MOL} / \mathrm{L})^{\square}$} & $12.2 \pm 4.6$ & $11.8 \pm 4.1$ & \multirow[t]{2}{*}{$0.710^{\mathrm{ns}}$} \\
\hline & $12.4(8.6-15.8)$ & $11.3(8.2-14.6)$ & \\
\hline \multirow[t]{2}{*}{ Troponin $(\mathrm{ng} / \mathrm{L})^{\star}$} & $6.9 \pm 6.1$ & $6.0 \pm 3.9$ & \multirow[t]{2}{*}{$0.534^{\mathrm{ns}}$} \\
\hline & $5.0(3.0-7.8)$ & $5.0(3.0-7.0)$ & \\
\hline \multirow[t]{2}{*}{ usPCR (mg/dL)* } & $9.6 \pm 15.0$ & $9.7 \pm 13.2$ & \multirow[t]{2}{*}{$0.985^{\mathrm{ns}}$} \\
\hline & $4.2(1.3-12.4)$ & $3.6(1.6-11.2)$ & \\
\hline \multirow[t]{2}{*}{ HBA1C (\%)* } & $6.3 \pm 1.9$ & $5.8 \pm 1.1$ & \multirow[t]{2}{*}{$0.271^{\mathrm{ns}}$} \\
\hline & $5.8(5.0-6.4)$ & $5.6(5.2-6.1)$ & \\
\hline \multirow[t]{2}{*}{ Insulin $(\mu \mathrm{UI} / \mathrm{mL})^{\star}$} & $16.6 \pm 13.2$ & $15.0 \pm 10.5$ & \multirow[t]{2}{*}{$0.604^{\mathrm{ns}}$} \\
\hline & $11.0(6.2-23.0)$ & $11.0(8.0-22.0)$ & \\
\hline \multirow[t]{2}{*}{ HOMA-IR* } & $6.0 \pm 7.8$ & $3.6 \pm 3.0$ & \multirow[t]{2}{*}{$0.197^{\mathrm{ns}}$} \\
\hline & $3.3(1.5-7.6)$ & $2.6(1.7-4.5)$ & \\
\hline CKMB- mass* & $2.7 \pm 3.2$ & $2.1 \pm 1.5$ & $0.434^{n s}$ \\
\hline
\end{tabular}




\begin{tabular}{|c|c|c|c|}
\hline & $1.5(1.0-3.0)$ & $2.0(1.0-2.0)$ & \\
\hline \multirow[t]{2}{*}{$\mathrm{SBP}(\mathrm{mm} \mathrm{Hg})^{\square}$} & $132.5 \pm 20.0$ & $127.3 \pm 17.5$ & \multirow[t]{2}{*}{$0.304^{\mathrm{ns}}$} \\
\hline & $130.0(120.0-147.5)$ & $130.0(110.0-140.0)$ & \\
\hline \multirow[t]{2}{*}{$\mathrm{DBP}(\mathrm{mm} \mathrm{Hg})^{\square}$} & $74.0 \pm 8.2$ & $74.6 \pm 9.9$ & \multirow[t]{2}{*}{$0.805^{\mathrm{ns}}$} \\
\hline & $70.0(70.0-80.0)$ & $80.0(70.0-80.0)$ & \\
\hline \multirow[t]{2}{*}{$\mathrm{RF}(\mathrm{UI} / \mathrm{mL})^{*}$} & $96.8 \pm 153.6$ & $297.9 \pm 561.5$ & \multirow[t]{2}{*}{$0.250^{\mathrm{ns}}$} \\
\hline & $32.0(4.0-112.0)$ & $64.0(8.0-256.0)$ & \\
\hline \multirow[t]{2}{*}{ DAS 28-PCR } & $4.1 \pm 1.4^{\# \#}$ & $4.4 \pm 1.5^{\# \#}$ & \multirow[t]{2}{*}{$0.372^{\mathrm{ns}}$} \\
\hline & $3.7(3.2-5.1)$ & $4.3(3.2-5.4)$ & \\
\hline \multirow[t]{2}{*}{$\mathrm{IL}-1 \mathrm{~b} *(\mathrm{pg} / \mathrm{mL})$} & $7.4 \pm 1.4$ & $11.1 \pm 10.8$ & \multirow[t]{2}{*}{$0.290^{\mathrm{ns}}$} \\
\hline & $7.0(6.4-8.6)$ & $8.4(6.0-10.6)$ & \\
\hline \multirow[t]{2}{*}{ TNF-a* $(p g / m L)$} & $52.3 \pm 23.4$ & $71.6 \pm 57.6$ & \multirow[t]{2}{*}{$0.608^{n s}$} \\
\hline & $42.8(41.6-57.7)$ & $50.2(37.2-97.0)$ & \\
\hline \multirow[t]{2}{*}{$\mathrm{IL}-6^{\square}(\mathrm{ng} / \mathrm{mL})$} & $67.9 \pm 67.6$ & $94.6 \pm 107.3$ & \multirow[t]{2}{*}{$0.248^{\mathrm{ns}}$} \\
\hline & $55.4(12.5-113.7)$ & $37.6(7.1-185.5)$ & \\
\hline \multirow[t]{2}{*}{ Myeloperoxidase ${ }^{\llbracket}(\mathrm{ng} / \mathrm{mL})$} & $198.1 \pm 100.6$ & $200.0 \pm 124.4$ & \multirow[t]{2}{*}{$0.954^{\mathrm{ns}}$} \\
\hline & $164.5(114.6-271.7)$ & $139.6(115.3-262.0)$ & \\
\hline \multicolumn{4}{|c|}{ student $t$ test for unpaired samples } \\
\hline \multicolumn{4}{|c|}{ no significant difference $(p \geq 0.05)$} \\
\hline \multicolumn{4}{|l|}{ Mann-Whitney Test } \\
\hline \multicolumn{4}{|l|}{${ }^{\# 1}$ volunteer excluded } \\
\hline \multicolumn{4}{|l|}{$\# \# 2$ excluded volunteers } \\
\hline \#\#\# 3 excluded volunteers & & & \\
\hline
\end{tabular}

In relation to cardiovascular risk assessment, using ACC/AHA, Guideline on the Treatment of Blood Cholesterol to Reduce Atherosclerotic Cardiovascular Risk in Adults, when we used four predictors (glucocorticoid dose, time of use of GCS, myeloperoxidase and PCR-us), considered together, these were responsible for predicting CVR significantly $\left(n=59, \chi^{2}=12.36, p=0.015\right)$.

Logistic regression analysis after adjustment showed a significant relationship with the predictor variable myeloperoxidase (Ratio of changes $=10.0 \mathrm{Cl} 95 \%=1.14-87.2, \mathrm{p}=0.037$ ), these results and CVR are 
expressed in Table 4.

Table 4. Effect of explanatory variables to predict the probability of cardiovascular risk obtained by logistic regression.

\begin{tabular}{|c|c|c|c|c|c|c|c|c|}
\hline \multirow[t]{2}{*}{ Variables } & \multirow[t]{2}{*}{$\beta$} & \multirow[t]{2}{*}{ S.E. } & \multirow[t]{2}{*}{ Wald } & \multirow[t]{2}{*}{$\mathrm{GI}$} & \multirow[t]{2}{*}{$\mathrm{p}$} & \multirow{2}{*}{$\begin{array}{l}\text { Odds } \\
\text { Ratio }\end{array}$} & \multicolumn{2}{|c|}{ C.I. $95 \%$} \\
\hline & & & & & & & Lower & Superior \\
\hline Dose of glucocorticoid & 0.60 & 0.68 & 0,76 & 1 & 0.382 & 1.82 & 0.48 & 6.93 \\
\hline Glucocorticoid time & 0.82 & 0.71 & 1,33 & 1 & 0.249 & 2.27 & 0.56 & 9.12 \\
\hline Myeloperoxidase & 2.30 & 1.11 & 4,34 & 1 & $0.037 *$ & 10.00 & 1.14 & 87.21 \\
\hline CRP & 0.80 & 0.80 & 1,01 & 1 & 0.315 & 2.23 & 0.47 & 10.57 \\
\hline Constant & -3.71 & 1.20 & 9,59 & -- & 0.115 & 0.002 & -- & -- \\
\hline
\end{tabular}

*significant difference $(p<0.05)$

\section{Discussion}

In the present study, the mean blood glucose of patients who did not use GCS was higher when compared to those who used this therapy. These data can be conflicting because it is known that the use of GCS can cause hyperinsulinemia, IR and an inhibiting effect on beta cell functions, which can lead to the development of DM $[15,16]$. However, these undesirable effects of using GCS may be dependent on dose and time of use. Some studies also point out that IR caused by the inflammatory process of RA is improved with low levels of GCS as inflammation is resolved, while moderate to high dose therapy can lead to hyperglycemia and overt DM $[9,16,17]$.

Another factor to be taken into account is that the glucose dosages of this study were performed fasting. It is known that fasting glucose concentrations are commonly normal in patients with Hyperglycemia induced by GCS. However, it is generally accepted that GCS cause an increase in post prandial glucose concentrations $[18,19]$. The onset of hyperglycemia should also be evaluated and the best time of day to dose blood glucose concentrations for appropriate early treatment in patients who are treated with moderate or high-dose steroids for the first time should be evaluated. In general, it is believed that GCS cause hyperglycemia after meals, with no consensus on the ideal screening time for hyperglycemia induced by this type of therapy[17]. In a cohort study conducted with patients using prednisolone for chronic obstructive pulmonary disease, postprandial glucose concentrations after lunch and dinner, measured using a continuous system of glucose monitoring, better predicted the occurrence of hyperglycemia [20]. Only fasting glucose measurement for the diagnosis of DM may not detect GCS induced hyperglycemia and DM induced by steroid therapy. On the contrary, postprandial hyperglycemia performed after lunch provides the best diagnostic accuracy. Pre-prandial glucose before dinner has the lowest sensitivity, despite its convenience $[17,21]$. 
It is also known that glucose metabolism is often impaired in patients with active and early RA, probably, at least in part, related to inflammation. Thus, short-term treatment with high doses of prednisone would not further deteriorate glycemic control, as determined in the fasting state and after an oral glucose load, in some patients. Studies show that there may be great variability among individuals, some of which may improve and others show deterioration in glucose tolerance. The use of GCS by patients with chronic inflammatory conditions may improve glucose tolerance via anti-inflammatory and disease-modifying effects, as has been demonstrated in several short-term studies [22].

Despite the various hypotheses raised and which may be related to the difference in blood glucose between the groups, it should be taken into account that the prevalence of individuals previously diagnosed with DM in the group that did not use GCS (25\%) was higher than that found in the group that uses this treatment (10\%). Although there was not significant difference in this research, this may be a contributing factor for the differences in blood glucose values between groups.

Regarding the CVS score, ACC/AHA, there was no significant difference between the groups regarding the use or not of GCS, when evaluated in isolation. However, after adjustment, when the variables "GCS dose", "time of use of use GCS", "PCR-us dosage" and "myeloperoxidase" were evaluated together, it was observed that significantly, they can be predictors of CVR when related to the score. However, when the variables were analyzed alone, Serum MPO is significantly shown as a predictor of CVR, different from the other variables analyzed in the set, which in isolation do not present themselves as predictors of CVR in patients with RA.

MPO has the ability to activate metalloproteinases of the latent matrix, in active forms, and may play an important role in sites of plate fissure. This includes the oxidation of LDL, turning it proatherogenic $[10,11,23]$ as well as oxidative modification of apolipoprotein Al, attenuating its ability to promote cholesterol efflux $[24,25]$. Studies indicate that MPO has been identified in human plaques and exerts potent pro-atherogenic effects, as well as evidence that its systemic levels serve as a strong and independent predictor of endothelial dysfunction in individuals. MPO activity also decreases the bioavailability of nitric oxide, which leads to endothelial dysfunction. This combination of harmful effects culminated in the concept that MPO can be an active mediator of atherogenesis, and high levels of MPO may be associated with increased CVR in apparently healthy individuals $[26,27]$.

It is clear that the elevation of inflammatory markers, such as MPO and us-CRP, and the interaction between them precedes in years the coronary artery disease. These biomarkers have potential relevance in the exploration of strategies for the prevent in and treatment of CVD in these patients, because they are responsible for approximately half of the deaths. Some studies have shown that cardiovascular events occur a decade earlier than in population controls [28]. Several publications have addressed the effects of risk factors related to RA on accelerated atherosclerosis, but most studies were cross-sectional, finding associations, but not necessarily causality [29]. Thus, the use of biomarkers that could serve as an aid tool in the preventive diagnosis of such complications would be relevant. 
In our study, it is not observed that the dose or time of use of GCS influence the CVR score when evaluated in isolation. Despite a few studies, little is known about the long-term effects of corticosteroid therapy on the development of CVD. Most studies evaluated exposure to GCS only as a single variable, for example, in initial, current or cumulative use [30,31]. Thus, cumulative measures of exposure to GCS, such as total duration of use or total cumulative dose, vary over time, which may have an influence on the risk of AMI. Efficient modeling of time-dependent GCS exposure measures is especially important, as knowledge about how CVR changes with increasing cumulative dose and/or duration of GCS is necessary to find an optimal balance between the anti-inflammatory benefits of GCS and increased CVR.

\section{Conclusion}

Our findings indicate that MPO is an important predictor of CVR in patients with RA, when associated with scores commonly used to assess this risk. This relationship seems to be present independently of the GCS dose or time of its usage. Based on these findings, there is a need for other prospective clinical trials to determine whether MPO is a reliable biomarker for predicting CVD in RA.

\section{Declarations}

\section{Ethics Approval}

The study was approved by the Committee of Research Ethics of the State University of Ponta Grossa (UEPG) through the "Brazil Platform" (opinion 1.879.373) in accordance with the Helsinki declaration of 1975, as revised in 1983.

\section{Consent for publication}

Free and informed consent form was obtained from all individual participants included in the study. All subjects have authorized anonymous publication of data research.

\section{Competing Interests}

The authors declare no competing interests.

\section{Availability of data and materials}

All survey data are available for consultation when requested.

\section{Funding}

There was no funding for the study

\section{Authors' contributions}


Elisangela Gueiber Montes, Marcelo Derbli Schafranski and José Carlos Rebluglio Vellosa contributed conception and design of the study, Rômulo Lopes da Costa, Lorena de Freitas Calixto and Felício de Freitas Netto collected and organized the database, Fábio André dos Santos performed the statistical analysis, Elisangela Gueiber Montes e José Carlos Rebuglio Vellosa wrote the first draft of the manuscript, all other authors wrote sections of the manuscript. All authors contributed to manuscript revision, read, and approved the submitted version.

\section{Acknowledgements}

Authors are grateful to the Regional University Hospital of Campos Gerais - Wallace Thadeu de Mello e Silva for having authorized the research to be carried out.

\section{References}

1. T.M. Hunter, N.N. Boytsov, X. Zhang, K. Schroeder, K. Michaud, A.B. Araujo, Prevalence of rheumatoid arthritis in the United States adult population in healthcare claims databases, 2004-2014, Rheumatol. Int. 37 (2017) 1551-1557. https://doi.org/10.1007/s00296-017-3726-1.

2. C. Negrei, V. Bojinca, A. Balanescu, M. Bojinca, D. Baconi, D.A. Spandidos, A.M. Tsatsakis, M. Stan, Management of rheumatoid arthritis: Impact and risks of various therapeutic approaches (Review), Exp. Ther. Med. 11 (2016) 1177-1183. https://doi.org/10.3892/etm.2016.3045.

3. V. Germano, M.S. Cattaruzza, J. Osborn, A. Tarantino, R. Di Rosa, S. Salemi, R. D’Amelio, Infection risk in Rheumatoid Arthritis and Spondyloarthropathy patients under treatment with DMARDs, Corticosteroids and TNF-a antagonists, J. Transl. Med. 12 (2014) 1-10. https://doi.org/10.1186/1479-5876-12-77.

4. I.B. Mclnnes, G. Schett, Mechanism of Disease The Pathogenesis of Rheumatoid Arthritis, N. Engl. J. Med. 365 (2011) 2205-2219.

5. J. Amaya-Amaya, J.C. Sarmiento-Monroy, R.D. Mantilla, R. Pineda-Tamayo, A. Rojas-Villarraga, J.M. Anaya, Novel risk factors for cardiovascular disease in rheumatoid arthritis, Immunol. Res. 56 (2013) 267-286. https://doi.org/10.1007/s12026-013-8398-7.

6. J. Braun, K. Krüger, B. Manger, M. Schneider, C. Specker, H.J. Trappe, Cardiovascular comorbidity in inflammatory rheumatological conditions, Dtsch. Arztebl. Int. 114 (2017) 197-203. https://doi.org/10.3238/arztebl.2017.0197.

7. F. Verhoeven, C. Prati, K. Maguin-Gaté, D. Wendling, C. Demougeot, Glucocorticoids and endothelial function in inflammatory diseases: Focus on rheumatoid arthritis, Arthritis Res. Ther. 18 (2016). https://doi.org/10.1186/s13075-016-1157-0.

8. J.A. Aviña-zubieta, M. Abrahamowicz, M.A. De vera, H.K. Choi, E.C. Sayre, M.M. Rahman, M.P. Sylvestre, W. Wynant, J.M. Esdaile, D. Lacaille, Immediate and past cumulative effects of oral glucocorticoids on the risk of acute myocardial infarction in rheumatoid arthritis: A population-based study, Rheumatol. (United Kingdom). 52 (2013) 68-75. https://doi.org/10.1093/rheumatology/kes353. 
9. J.F. Ferreira, A.A. Ahmed Mohamed, P. Emery, Glucocorticoids and Rheumatoid Arthritis, Rheum. Dis. Clin. North Am. 42 (2016) 33-46. https://doi.org/10.1016/j.rdc.2015.08.006.

10. A. Daugherty, J.L. Dunn, D.L. Rateri, J.W. Heinecke, Myeloperoxidase, a catalyst for lipoprotein oxidation, is expressed in human atherosclerotic lesions, J. Clin. Invest. 94 (1994) 437-444. https://doi.org/10.1172/JCl117342.

11. M.C. Meuwese, E.S.G. Stroes, S.L. Hazen, J.N. van Miert, J.A. Kuivenhoven, R.G. Schaub, N.J. Wareham, R. Luben, J.J.P. Kastelein, K.T. Khaw, S.M. Boekholdt, Serum Myeloperoxidase Levels Are Associated With the Future Risk of Coronary Artery Disease in Apparently Healthy Individuals. The EPIC-Norfolk Prospective Population Study, J. Am. Coll. Cardiol. 50 (2007) 159-165. https://doi.org/10.1016/j.jacc.2007.03.033.

12. R. Patel, L. Magomedova, R. Tsai, S. Angers, A. Orellana, C.L. Cummins, Separating the antiinflammatory and diabetogenic effects of glucocorticoids through LXRß antagonism, Endocrinology. 158 (2017) 1034-1047. https://doi.org/10.1210/en.2017-00094.

13. D. Aletaha, T. Neogi, A.J. Silman, J. Funovits, D.T. Felson, C.O. Bingham, N.S. Birnbaum, G.R. Burmester, V.P. Bykerk, M.D. Cohen, B. Combe, K.H. Costenbader, M. Dougados, P. Emery, G. Ferraccioli, J.M.W. Hazes, K. Hobbs, T.W.J. Huizinga, A. Kavanaugh, J. Kay, T.K. Kvien, T. Laing, P. Mease, H.A. Ménard, L.W. Moreland, R.L. Naden, T. Pincus, J.S. Smolen, E. Stanislawska-Biernat, D. Symmons, P.P. Tak, K.S. Upchurch, J. Vencovský, F. Wolfe, G. Hawker, 2010 Rheumatoid arthritis classification criteria: An American College of Rheumatology/European League Against Rheumatism collaborative initiative, Arthritis Rheum. 62 (2010) 2569-2581. https://doi.org/10.1002/art.27584.

14. D.M.F.M. Van Der Heijde, M.A. Van't Hof, P.L.C.M. Van Riel, L.A.M. Theunisse, E.W. Lubberts, M.A. Van Leeuwen, M.H. Van Rijswijk, L.B.A. Van De Putte, Judging disease activity in clinical practice in rheumatoid arthritis: First step in the development of a disease activity score, Ann. Rheum. Dis. 49 (1990) 916-920. https://doi.org/10.1136/ard.49.11.916.

15. N.J. Stone, J.G. Robinson, A.H. Lichtenstein, C.N. Bairey Merz, C.B. Blum, R.H. Eckel, A.C. Goldberg, D. Gordon, D. Levy, D.M. Lloyd-Jones, P. McBride, J.S. Schwartz, S.T. Shero, S.C. Smith, K. Watson, P.W.F. Wilson, 2013 ACC/AHA guideline on the treatment of blood cholesterol to reduce atherosclerotic cardiovascular risk in adults: A report of the American college of cardiology/American heart association task force on practice guidelines, J. Am. Coll. Cardiol. 63 (2014) 2889-2934. https://doi.org/10.1016/j.jacc.2013.11.002.

16. E. Mills, S. Devendra, Steroid-induced hyperglycaemia in primary care, London J. Prim. Care (Abingdon). 7 (2015) 103-106. https://doi.org/10.1080/17571472.2015.1082344.

17. G.B. Cansu, D.Ü. Cansu, B. Taşkıran, Ş.Y. Bilge, M. Bilgin, C. Korkmaz, What is the optimal time for measuring glucose concentration to detect steroid-induced hyperglycemia in patients with rheumatic diseases?, Clin. Biochem. 67 (2019) 33-39. https://doi.org/10.1016/j.clinbiochem.2019.03.012.

18. Y. Ogawa, K. Tomotsune, T. Suda, Glucocorticoid-induced diabetes, Nippon Rinsho. Japanese J. Clin. Med. 63 Suppl 2 (2005) 324-328. 
19. M.C. Gulliford, J. Charlton, R. Latinovic, Risk of Diabetes Associated With Prescribed Glucocorticoids in a Large Population, (2006). https://doi.org/10.2337/dc06-1499.

20. S. Lillegraven, J.D. Greenberg, G.W. Reed, K. Saunders, J.R. Curtis, L. Harrold, M.C. Hochberg, D.A. Pappas, J.M. Kremer, D.H. Solomon, Immunosuppressive treatment and the risk of diabetes in rheumatoid arthritis, PLoS One. 14 (2019) 1-10. https://doi.org/10.1371/journal.pone.0210459.

21. M.G. Burt, G.W. Roberts, N.R. Aguilar-Loza, P. Frith, S.N. Stranks, Continuous Monitoring of Circadian Glycemic Patterns in Patients Receiving Prednisolone for COPD, (2011). https://doi.org/10.1210/jc.2010-2729.

22. S. Kwon, K.L. Hermayer, Glucocorticoid-induced hyperglycemia, in: Am. J. Med. Sci., 2013: pp. 274277. https://doi.org/10.1097/MAJ.0b013e31828a6a01.

23. D. Den Uyl, D.H. Van Raalte, M.T. Nurmohamed, W.F. Lems, J.W.J. Bijlsma, J.N. Hoes, B.A.C. Dijkmans, M. Diamant, Metabolic effects of high-dose prednisolone treatment in early rheumatoid arthritis: Balance between diabetogenic effects and inflammation reduction, Arthritis Rheum. 64 (2012) 639646. https://doi.org/10.1002/art.33378.

24. E.A. Podrez, D. Schmitt, H.F. Hoff, S.L. Hazen, Myeloperoxidase-generated reactive nitrogen species convert LDL into an atherogenic form in vitro, J. Clin. Invest. 103 (1999) 1547-1560. https://doi.org/10.1172/JCl5549.

25. E. Malle, G. Marsche, U. Panzenboeck, W. Sattler, Myeloperoxidase-mediated oxidation of highdensity lipoproteins: Fingerprints of newly recognized potential proatherogenic lipoproteins, Arch. Biochem. Biophys. 445 (2006) 245-255. https://doi.org/10.1016/j.abb.2005.08.008.

26. A.A. Memon, M. Zarrouk, S. Ågren-Witteschus, J. Sundquist, A. Gottsäter, K. Sundquist, Identification of novel diagnostic and prognostic biomarkers for abdominal aortic aneurysm, Eur. J. Prev. Cardiol. 27 (2020) 132-142. https://doi.org/10.1177/2047487319873062.

27. S.J. Nicholls, S.L. Hazen, Myeloperoxidase and cardiovascular disease, Arterioscler. Thromb. Vasc. Biol. 25 (2005) 1102-1111. https://doi.org/10.1161/01.ATV.0000163262.83456.6d.

28. N.A. Khan, G. Lawyer, S. McDonough, Q. Wang, N.O. Kassem, F. Kas-Petrus, D. Ye, K.P. Singh, N.O.F. Kassem, I. Rahman, Systemic biomarkers of inflammation, oxidative stress and tissue injury and repair among waterpipe, cigarette and dual tobacco smokers, Tob. Control. 29 (2019) 102-109. https://doi.org/10.1136/tobaccocontrol-2019-054958.

29. P.A. Bacon, R.J. Stevens, D.M. Carruthers, S.P. Young, G.D. Kitas, Accelerated atherogenesis in autoimmune rheumatic diseases, Autoimmun. Rev. 1 (2002) 338-347. https://doi.org/10.1016/S1568-9972(02)00100-3.

30. J.E. Pope, T. Nevskaya, L. Barra, G. Parraga, Carotid Artery Atherosclerosis in Patients with Active Rheumatoid Arthritis: Predictors of Plaque Occurrence and Progression Over 24 Weeks, Open Rheumatol. J. 10 (2016) 49-59. https://doi.org/10.2174/1874312901610010049.

31. J.M. Davis, H.M. Kremers, C.S. Crowson, P.J. Nicola, K. V. Ballman, T.M. Therneau, V.L. Roger, S.E. Gabriel, Glucocorticoids and cardiovascular events in rheumatoid arthritis: A population-based cohort study, Arthritis Rheum. 56 (2007) 820-830. https://doi.org/10.1002/art.22418. 
32. L. Wei, T.M. MacDonald, B.R. Walker, Taking glucocorticoids by prescription is associated with subsequent cardiovascular disease, Ann. Intern. Med. 141 (2004). https://doi.org/10.7326/00034819-141-10-200411160-00007.

\section{Supplementary Files}

This is a list of supplementary files associated with this preprint. Click to download.

- okGRAPHICALABSTRACTInflammation.tif 